\title{
Pengaruh penambahan bentangan horizontal pada pancing dasar terhadap hasil tangkapan ikan-ikan karang
}

\author{
Effect of horizontal stretch on bottom hand lines to reef fish catch
}

\author{
ROLAND P. KATIMPALI ${ }^{*}$, ISROJATY J. PARANSA dan MARIANA E. KAYADOE \\ Program Studi Pemanfaatan Sumberdaya Perikanan, Fakultas Perikanan dan Ilmu Kelautan, \\ Universitas Sam Ratulangi, Manado 95115
}

\begin{abstract}
The design of traditional bottom hand line, locally called ba lot, used for coral fish fishing has problems on the branch line in operation, in which when it is lowered and hauled up, the main line is easily entangled to the branch line due to very close to each other. To increase the gear efficiency and success, a study was carried out through fishermen-made bottom hand line design modification for future development. This study was aimed at understanding the effect of horizontal range increment from the main line on catches and identifying the fish catch. It was done in Manado Bay waters, Maasing District using the traditional fishing operation. Data were collected using 6 units of bottom hand lines ( 3 units of fishermen-made hand lines and 3 units of modified bottom hand lines with an additional horizontal stretch) at the same time in 10 fishing operations. Catch data were analyzed using a paired t-test. Total catches were 80 fish, 30 fish by fishermen-made gears and 50 fish by modified gears. Those were pale snapper (Etelis radiosus), rosy snapper (Pristipomoides filamentosus), giant travelly (Caranx ignobilis), lyre tail cod (Epinephelus sp.) and silky shark (Carcharhinus falciformis)
\end{abstract}

Keywords: reef fish, bottom hand lines, modified bottom hand lines

\begin{abstract}
ABSTRAK
Disain pancing dasar atau "ba lot" buatan nelayan yang digunakan untuk menangkap ikan karang, pada saat pelaksanaan pengoperasian, ternyata terdapat masalah pada tali cabang yaitu: tali cabang terlalu dekat dengan tali utama yang mengakibatkan tali cabang mudah terbelit pada tali utama saat pancing diulurkan maupun dinaikkan. Untuk meningkatkan efisiensi dan efektifitas alat tangkap, maka harus dilakukan penelitian demi pengembangannya dengan perbaikan desain atau modifikasi pancing dasar buatan nelayan tersebut. Tetapi informasi ilmiah tentang aplikasinya belum tersedia. Penelitian ini bertujuan untuk mempelajari pengaruh penambahan bentangan horizontal pada pancing dasar terhadap hasil tangkapan ikan-ikan karang dan mengidentifikasi jenis-jenis ikan karang yang tertangkap. Penelitian ini dilakukan di perairan pantai Teluk Manado, Kecamatan Maasing; dengan mengikuti metode eksperimental. Teknik pengumpulan data dilakukan dengan cara mengoperasikan 6 unit alat tangkap pancing dasar (3 unit pancing dasar buatan nelayan dan 3 unit pancing dasar modifikasi dengan memberi bentangan horizontal) secara bersamaan selama 10 trip. Data tangkapan dianalisis dengan uji-t berpasangan. Hasil tangkapan yang diperoleh selama pengoperasian pancing dasar adalah berjumlah 80, dimana 30 ekor tertangkap dengan pancing dasar buatan nelayan dan 50 ekor lainnya tertangkap dengan pancing dasar modifikasi yang teridentifikasi yaitu kurisi (Etelis radiosus), kurisi bali (Pristipomoides filamentosus), kuwe (Caranx ignobilis), kerapu (Epinephelus sp.) dan cucut (Carcharhinus falciformis)
\end{abstract}

Kata-kata kunci: ikan karang, pancing dasar, pancing modifikasi

\section{PENDAHULUAN}

Pancing dasar merupakan salah satu alat tangkap yang selektif dan cenderung ramah lingkungan

\footnotetext{
* Penulis untuk penyuratan: e-mail:

roland.pedro25@yahoo.com
}

jika dioperasikan secara tepat dan relatif murah. Masyarakat nelayan di Kecamatan Maasing, mengenal pancing dasar dengan sebutan pancing "ba lot". Menurut Katiandagho dan Kumajas (1987) bahwa terdapat beberapa segi positif dari perikanan pancing, diantaranya adalah struktur dan 
operasi penangkapan ikan mudah dilaksanakan, organisasi usaha kecil dimana dengan modal sedikit usaha sudah dapat berjalan, syarat daerah penangkapan ikan relatif sedikit dan dapat dipilih dengan mudah, ikan yang tertangkap seekor demi seekor sehingga kesegarannya terjamin. Berbeda spesies ikan yang akan menjadi tujuan penangkapan maka akan berbeda pula jenis pancing yang akan digunakan; hal ini banyak menyebabkan variasi pancing. Sedangkan segi negatifnya dalam hasil tangkapannya sedikit serta sifatnya pasif (Katiandagho dkk., 1989). Untukmeningkatkan efisiensi alat tangkap ini, perlu dilakukan penelitian-penelitian demi pengembangannya, baik perbaikan desain atau modifikasi alat itu sendiri maupun tingkah laku ikan yang menjadi target penangkapan.

Dalam mengoperasikan alat ini, nelayan biasanya membawa cadangan tali cabang yang cukup banyak atau beberapa unit alat tangkap ke daerah penangkapan ikan. Hal ini merupakan tindakan antisipasi karena alat tangkap ini mudah putus pada saat pengoperasian. Jika tidak diantisipasi maka nelayan terpaksa membuat lagi konstruksi satu unit pancing dasar saat berada di lokasi pengoperasian. Hal ini dapat mengganggu efisiensi dan efektifitas penggunaan alat tangkap pancing dasar, terutama jika saat itu ikan sedang bernafsu memakan umpan.

Pada konstruksi alat pancing dasar buatan nelayan ini, tali cabang disambung langsung dengan tali utama yang mengakibatkan tali cabang mudah terbelit pada tali utama saat pancing diulurkan maupun dinaikkan. Sehingga perlu alternatif pemecahan permasalahan, yaitu memberikan lengan atau media bentangan yang memberikan jarak antara tali utama dan tali cabang. Media ini terbuat dari kawat tembaga yang berbentuk menyerupai kili-kili (swivel) kaki tiga, yang salah satu bagiannya lebih panjang, yang disebut bentangan horizontal yang berfungsi sebagai tempat mengikat kili-kili dan tali cabang agar jarak tali cabang cukup jauh dari tali utama.

Modifikasi ini dilakukan dengan mengadopsi dari alat pancing "papiti" dengan satu mata pancing dimana alat pancing tersebut sering digunakan oleh para pemancing ikan tuna. Alat ini bagi pemancing tuna sangat efektif karena dapat diturunkan dengan cepat ke dasar perairan tanpa harus khawatir tali cabang melingkari pada tali utama. Dari upaya modifikasi ini, diharapkan dapat mengatasi persoalan yang dihadapi nelayan. Oleh karena itu, dipandang perlu melakukan penelitian membandingkan pengaruh penambahan bentangan horizontal dengan kawat tembaga pada pancing dasar terhadap hasil tangkapan ikan-ikan karang. Penelitian ini bertujuan untuk mempelajari pengaruh penambahan bentangan horizontal pada pancing dasar terhadap hasil tangkapan ikan-ikan karang dan mengidentifikasi jenis-jenis ikan karang yang tertangkap.

\section{METODE PENELITIAN}

Penelitian ini dilakukan di perairan pantai Teluk Manado, Kecamatan Maasing, Kelurahan Tuminting; dengan mengikuti metode eksperimental (Nursyahidah, 2012). Hipotesis dasar $\left(\mathrm{H}_{0}\right)$ penelitian ini adalah pancing dasar yang menggunakan bentangan horizontal menghasilkan tangkapan dalam jumlah yang sama dengan pancing dasar tanpa bentangan horizontal. Sedangkan hipotesis alternatifnya $\left(\mathrm{H}_{1}\right)$ adalah pancing dasar yang menggunakan bentangan horizontal menghasilkan tangkapan dalam jumlah yang berbeda dengan pancing dasar tanpa bentangan horizontal. Teknik pengumpulan data dilakukan dengan cara mengoperasikan 6 unit alat tangkap pancing dasar (3 unit pancing dasar modifikasi dan 3 unit pancing dasar buatan nelayan) secara bersamaan selama 10 trip dengan menggunakan umpan ikan layang biru (Decapterus macarellus). Hasil tangkapan pancing dasar pada setiap pengamatan diukur, dicatat dan diidentifikasi berdasarkan pada masing-masing perlakuan. Untuk menguji hipotesis digunakan ujit pengamatan berpasangan (Steel and Torrie, 1993) dengan rumus:

$t=\frac{\bar{X}-\bar{Y}}{\sqrt{S_{\bar{D}}}} ; \quad S_{\bar{D}}=\frac{\sum D^{2}-\left(\sum D\right)^{2} / n}{n-1}$

atau

$t=\frac{\bar{X}-\bar{Y}}{\sqrt{\frac{\sum D^{2}-\left(\sum D\right)^{2} / n}{n-1}}}$

dimana:

$\bar{X}=$ hasil tangkapan pancing dasar modifikasi

$\bar{Y}=$ hasil tangkapan pancing dasar nelayan

Taraf nyata $(\alpha)=5 \%(0,05) ; D=\bar{X}-\bar{Y}$ 


\section{HASIL DAN PEMBAHASAN}

\section{Deskripsi alat tangkap}

Pancing adalah salah satu alat tangkap yang umum dikenal oleh masyarakat ramai terutama di kalangan nelayan. Pada prinsipnya pancing ini terdiri dari dua komponen utama, yaitu tali (line) dan mata pancing (hook) (Subani dan Barus, 1983). Pada dasarnya alat tangkap pancing dasar buatan nelayan terdiri dari penggulung tali (spool), tali utama (main line), tali cabang (branch line), kili-kili, manik-manik, mata pancing dan umpan. Sedangkan bagian-bagian pancing dasar modifikasi sama seperti buatan nelayan hanya pada tali utama ke tali cabang menggunakan lengan menyerupai kili-kili kaki 3 dengan bentangan horizontal tanpa manik-manik. Bagianbagian dari pancing ini adalah:

\section{Penggulung tali}

Penggulung tali terbuat dari material plastik dengan diameter luar $310 \mathrm{~mm}$ dan dalam $150 \mathrm{~mm}$ pada pancing buatan nelayan dan pada pancing dasar modifikasi penggulung terbuat dari material kayu dengan diameter luar $190 \mathrm{~mm}$ dan dalam 95 $\mathrm{mm}$. Penggulung tali berfungsi sebagai tempat untuk menggulung tali pancing, sebagai pegangan pada saat pengoperasian alat dan tempat untuk mengaitkan mata pancing setiap kali selesai melakukan operasi penangkapan ikan. Penggulung yang digunakan berbentuk bulat masing-masing berjumlah 3 buah untuk alat pancing dasar buatan nelayan dan pancing dasar modifikasi.

\section{Tali utama}

Tali utama berfungsi sebagai pengantar pemberat dan rangkaian pancing ke dasar perairan. Tali utama pancing dasar buatan nelayan terbuat dari bahan PA monofilamen no 800 dengan panjang $300 \mathrm{~m}$. Sedangkan untuk pancing dasar modifikasi, tali utama terbuat dari bahan damyl no 80 dan panjang tali utama $300 \mathrm{~m}$.

\section{Tali cabang}

Panjang tali cabang untuk pancing dasar buatan nelayan dan pancing dasar modifikasi adalah sama yaitu $0,6 \mathrm{~m}$ dengan bahan yang berbeda yaitu PA monofilamen no 600 untuk pancing dasar buatan nelayan dan damyl no 60 untuk pancing dasar modifikasi. Fungsi tali cabang sebagai tempat untuk mengikat mata pancing. Masing- masing jumlah tali cabang adalah 3 buah dengan jarak tali cabang untuk pancing dasar modifikasi dan pancing dasar buatan nelayan adalah sama yaitu $1,20 \mathrm{~m}$.

\section{Mata pancing}

Mata pancing berfungsi sebagai tempat mengaitkan umpan agar dimakan ikan target sehingga tertangkap; ukuran dan material mata pancing untuk pancing dasar buatan nelayan dan pancing dasar modifikasi adalah sama dari bahan stainless steel (SST) nomor 9 dan panjang (shank) $50 \mathrm{~mm}$.

\section{Kili-kili}

Fungsi kili-kili yang dipasang pada tali utama adalah agar tidak kusut pada saat pengoperasian seluruh rangkaian alat tangkap. Fungsi kili-kili yang dipasang pada tali cabang untuk menghindari tali cabang dengan mata kail yang berumpan tidak terbelit pada tali utama. Pada pancing dasar buatan nelayan digunakan kili-kili no 2 dan no 4 terbuat dari bahan SST. Sedangkan pada pancing dasar modifikasi menggunakan kili-kili no 1 dan 2 terbuat dari bahan brass.

\section{Manik-manik}

Manik-manik terbuat dari plastik yang berdiameter $8 \mathrm{~mm}$ hanya dipasang pada tali utama pancing dasar buatan nelayan yang dirangkai dengan simpul mati. Fungsi manik-manik untuk menahan kili-kili agar tidak bergerak atau berpindah dari posisi yang diinginkan, tetapi kili-kili itu sendiri dapat berputar secara bebas.

\section{Lengan dengan bentangan horizontal}

Lengan ini terbuat dari material kawat tembaga $\mathrm{Cu})$ hanya terdapat pada pancing dasar modifikasi; lengan ini menyerupai kili-kili kaki 3 berfungsi sebagai penghubung tali utama ke tali cabang; lengan ini berdiameter $6 \mathrm{~mm}$ dan panjang $23 \mathrm{~mm}$; yang salah satu bagian lebih panjang yang disebut bentangan horizontal. Fungsi bentangan horizontal yaitu untuk memberi jarak tali cabang dengan tali utama agar supaya terhindar dari terbelitnya tali cabang bersama mata pancing pada tali utama. Bentangan ini terbuat dari kawat tembaga yang mempunyai panjang $15 \mathrm{~cm}$ dengan diameter luar $6 \mathrm{~mm}$, dalam $5,3 \mathrm{~mm}$, dan penampang $0,7 \mathrm{~mm}$.

\section{Pemberat}

Pemberat terbuat dari besi yang berfungsi untuk menenggelamkan seluruh rangkaian pancing dasar buatan nelayan dan pancing dasar menggunakan bentangan ke dasar perairan, dan untuk 
mempertahankan mata pancing pada posisi yang diinginkan dan tidak hanyut terbawa arus. Pemberat 800 gr digunakan pada waktu arus kuat dan 400 gr pada saat tidak berarus dan arus sedang.

\section{Hasil tangkapan}

Hasil tangkapan yang diperoleh selama pengoperasian pancing dasar yang diberi bentangan horizontal dan pancing dasar tanpa bentangan buatan nelayan adalah berjumlah 80 ekor, dimana 30 ekor tertangkap dengan pancing dasar tanpa bentangan dan 50 ekor lainnya tertangkap dengan pancing dasar yang diberi bentangan. Hasil tangkapan yang teridentifikasi yaitu kurisi (Etelis radiosus), kurisi bali (Pristipomoides filamentosus), kuwe (Caranx ignobilis), kerapu (Epinephelus sp.) dan cucut (Carcharhinus falciformis).

Tabel 1. Spesifikasi pancing dasar tanpa bentangan horizontal

\begin{tabular}{|c|c|c|c|c|c|c|c|}
\hline No & Bagian & Material & No & $\begin{array}{l}\text { Diameter } \\
(\mathrm{mm})\end{array}$ & $\begin{array}{c}\text { Panjang } \\
(\mathrm{m})\end{array}$ & $\begin{array}{c}\text { Berat } \\
\text { (gr) }\end{array}$ & $\begin{array}{c}\text { Jumlah } \\
\text { (bh) }\end{array}$ \\
\hline & Penggulung & Plastik & - & 310 & - & 150 & 1 \\
\hline 2. & Tali utama & PA Mono & 800 & 0.7 & 300 & 300 & 1 \\
\hline & Tali cabang & PA Mono & 600 & 0.55 & 0.60 & 100 & 1 \\
\hline & Mata pancing & SST & 9 & - & 0.05 & 1 & 3 \\
\hline & Kili-kili & SST & 4 & - & 0.056 & 3 & 1 \\
\hline & & SST & 2 & 6 & 0.023 & 2 & 3 \\
\hline & Manik-manik & Plastik & - & 8 & - & - & 6 \\
\hline & Pemberat & $\mathrm{Fe}$ & - & & - & $\begin{array}{r}400 * \\
800 * *\end{array}$ & $\begin{array}{l}1 \\
1\end{array}$ \\
\hline
\end{tabular}

Keterangan : *Arus sedang **Arus kuat

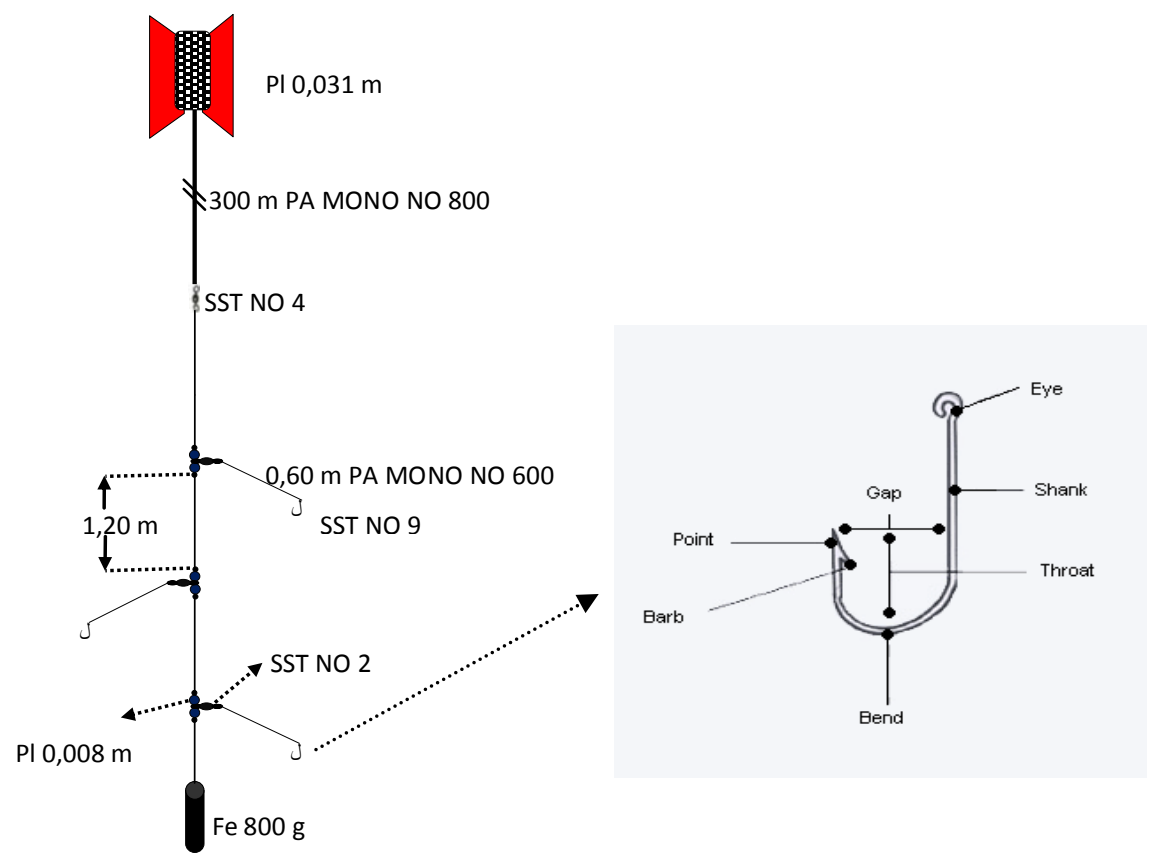

Gambar 1. Disain pancing dasar tanpa bentangan horizontal 
R.P. Katimpali dkk.

Tabel 2. Spesifikasi pancing dasar yang diberi bentangan horizontal

\begin{tabular}{lllrccrc}
\hline No & \multicolumn{1}{c}{ Bagian } & Material & $\begin{array}{c}\text { No } \\
\text { Diameter } \\
(\mathrm{mm})\end{array}$ & $\begin{array}{c}\text { Panjang } \\
(\mathrm{m})\end{array}$ & $\begin{array}{c}\text { Berat } \\
(\mathrm{gr})\end{array}$ & $\begin{array}{c}\text { Jumlah } \\
(\mathrm{bh})\end{array}$ \\
\hline 1. & Penggulung & Kayu & - & 190 & - & 300 & 1 \\
2. & Tali utama & Damyl & 80 & 0.8 & 300 & 300 & 1 \\
3. & Tali cabang & Damyl & 60 & 0.6 & 0.60 & 100 & 1 \\
4. & Mata pancing & SST & 9 & - & 0.05 & 1 & 3 \\
5. & Kili-kili & Brass & 2 & 5.2 & 0.0144 & 2 & 1 \\
& & 1 & 0.5 & 0.0124 & 1.6 & 3 \\
6. & Lengan & CU & & 6 & 0.023 & - & 6 \\
7. & Bentangan horizontal & CU & & 0.7 & 0.15 & 5 & 1 \\
8. & Pemberat & Fe & - & & - & $400^{*}$ & 1 \\
& & & & & & $800^{* *}$ & 1 \\
\hline
\end{tabular}

Keterangan : *Arus sedang **Arus kuat

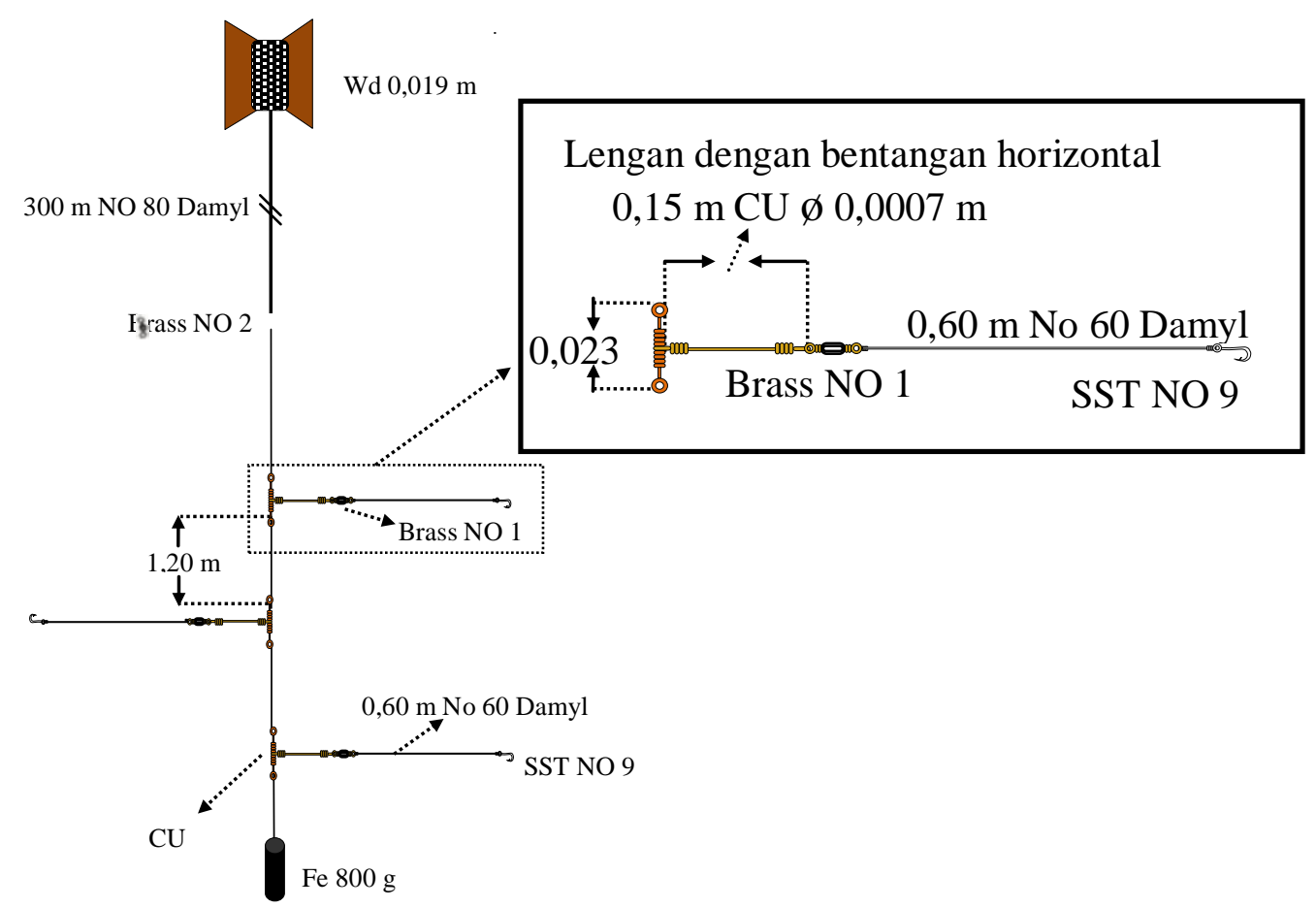

Gambar 2. Disain pancing dasar yang menggunakan bentangan horizontal

\section{Hasil analisis}

Data penelitian (Tabel 3) menunjukkan bahwa hasil tangkapan pancing dasar yang menggunakan bentangan horizontal lebih banyak dibanding jumlah hasil tangkapan pancing dasar tanpa bentangan horizontal.

Hasil analisis menunjukkan bahwa t-hitung $=$ 2,450 > t-tabel $\mathrm{l}_{0,05 ; 9}=1,833$; sehingga menerima $\mathrm{H}_{1}$ dan menolak $\mathrm{H}_{0}$, dimana hal ini menjelaskan bahwa penggunaan pancing dasar yang menggunakan bentangan horizontal berbeda nyata dengan pancing dasar tanpa bentangan horizontal terhadap hasil tangkapan ikan-ikan karang pada tingkat kepercayaan $95 \%$.

Fakta yang ditemukan di lapangan antara lain adalah pada pancing dasar tanpa bentangan horizontal tali cabangnya sering terbelit ke tali utama, terutama pada saat tali pancing dinaikkan dari dasar perairan ke atas perahu. Hal terbelit dapat juga terjadi pada saat pancing diturunkan, tetapi nelayan mengantisipasinya dengan cara 
menyentak-nyentakkan tali pancing berulangulang pada saat pemberat mencapai dasar perairan. Hal ini tidak dapat divisualisasikan karena keterbatasan peralatan penelitian. Proses terbelitnya tali cabang ini teramati ketika alat pancing dasar tanpa bentangan horizontal telah berada di atas perahu, saat mengontrol apakah umpan sudah dimakan ikan atau belum. Pengontrolan ini akan mempengaruhi waktu efektif penangkapan. Waktu yang dibutuhkan untuk membuka tali cabang yang terbelit sekitar 3 menit. Kondisi tali cabang terbelit pada pancing dengan bentangan horizontal tidak ditemukan, sehingga pancing dapat segera diulurkan kembali setelah diberi umpan. Hal ini membuat alat pancing dasar yang menggunakan bentangan horizontal lebih besar peluangnya menangkap ikan karena waktu efektif pengoperasiannya yang lebih panjang.

Tabel 3. Analisis perbandingan nilai tengah contoh pengamatan berpasangan terhadap hasil tangkapan berdasarkan perlakuan

\begin{tabular}{ccccc}
\hline Trip & $\mathrm{X}$ & $\mathrm{Y}$ & $\mathrm{D}=(\mathrm{X}-\mathrm{Y})$ & $\mathrm{D}^{2}$ \\
\hline 1 & 4 & 2 & 2 & 4 \\
2 & 6 & 3 & 3 & 9 \\
3 & 7 & 5 & 2 & 4 \\
4 & 4 & 1 & 3 & 9 \\
5 & 8 & 6 & 2 & 4 \\
6 & 5 & 2 & 3 & 9 \\
7 & 3 & 2 & 1 & 1 \\
8 & 6 & 4 & 2 & 4 \\
9 & 4 & 3 & 1 & 1 \\
10 & 3 & 2 & 1 & 1 \\
\hline Total & 50 & 30 & 20 & 46 \\
\hline Rataan & 5 & 3 & & \\
X = Pancing modifikasi & & & \\
Y = Pancing Nelayan & & &
\end{tabular}

$\bar{X}=5 ; \quad \bar{Y} ; \quad(\Sigma D)^{2}=20^{2}=400 ; \quad \Sigma D^{2}=46 ;$ $\mathrm{n}=10$; Taraf nyata $(\alpha)=5 \%(0,05)$; Nilai t-tabel dengan derajat bebas $(\mathrm{db})=\mathrm{n}-1=9$ adalah $\mathrm{t}_{0,05 ; 9}$ $=1,833$.

$$
\begin{aligned}
& t=\frac{\bar{X}-\bar{Y}}{\sqrt{\frac{\sum D^{2}-\left(\sum D\right)^{2} / n}{n-1}}} \\
& =\frac{5-3}{\sqrt{\frac{46-400 / 10}{10-1}}}=\frac{2}{\sqrt{\frac{46-40}{9}}}=2,450
\end{aligned}
$$

Operasi penangkapan dilakukan mengikuti kebiasaan nelayan sehingga waktu operasi tidak berdasarkan interval yang tepat. Kebiasaan nelayan adalah pengetahuan nelayan itu sendiri dan faktor alam misalnya cuaca sangat mempengaruhi pelaksanaan operasi terutama kondisi perairan yang bergelombang ataupun arus yang kuat, angin yang bertiup kencang dan hujan deras.

Dalam penelitian ini, penggunaan pemberat untuk kedua pancing ini adalah 400 gr, tetapi jika nelayan menganggap bahwa saat itu arus kuat maka mereka akan menggunakan pemberat dengan ukuran 800 gr. Arus kuat terjadi biasanya pada saat bulan kuartir, sesuai umur bulan dilangit

Dari beberapa kali pelaksanaan operasi penangkapan, muncul pertanyaan-pertanyaan dari nelayan bagaimana memperoleh material untuk membuat lengan atau bentangan horizontal pada tali pancing dasar yang dimodifikasi dan dimana material ini bisa diperoleh. Ini berarti nelayan tertarik untuk membuat alat serupa dalam hal merangkai bentangan horizontal ini mereka merasa tidak sulit untuk membuatnya karena konstruksinya mudah dan sederhana.

\section{ACKNOWLEDGEMENT}

Banyak pihak yang telah dilibatkan dalam penyusunan penelitian ini, untuk itu penulis menyampaikan terima kasih antara lain kepada Bapak Poni Telleng, Bapak Arman, Bapak Sunu dan nelayan di Kecamatan Maasing.

\section{KESIMPULAN}

1. Pancing dasar yang menggunakan bentangan horizontal lebih baik penggunaannya dibanding pancing dasar tanpa bentangan horizonal buatan nelayan.

2. Hasil tangkapan yang teridentifikasi yaitu kurisi, kurisi bali, kuwe, kerapu dan cucut.

\section{DAFTAR PUSTAKA}

Allen, G. 1999. Marine Fishes of South Asia. Periplus Edition (HK) Ltd, Australia.

Nursyahidah, F. 2012. Penelitian Eksperimen. http:// faridanursyahidah.files.wordpress.com/2012/05/penelitian eksperimen_farida, diakses tanggal 27 November 2012.

Katiandagho, E.M. dan H.J. Kumajas. 1987. Metode Penangkapan Ikan. Diktat Kuliah Fakultas Perikanan Universitas Sam Ratulangi, Manado. 
R.P. Katimpali dkk.

Katiandagho, E.M., H.J. Kumajas, dan A. Paturusi. 1989. Metode Penangkapan Ikan. Diktat kuliah Fakultas Perikanan. Universitas Sam Ratulangi, Manado.

Subani, W. dan H.A. Barus, 1988/1989. Alat penangkapan ikan dan udang laut di Indonesia. Jurnal Penelitian Perikanan Laut 50: 187.
Steel R.G.D. dan J.H. Torrie. 1993. Prinsip dan Prosedur Statistika: Suatu Pendekatan Biometrik. Diterjemahkan oleh B. Sumantri. Gramedia Pustaka Utama, Jakarta. 